\title{
Mortality and morbidity after initial diagnostic excision biopsy of cutaneous melanoma in primary versus secondary care
}

\begin{abstract}
Background

Current UK melanoma guidelines do not support the initial diagnostic excision biopsy of pigmented lesions in primary care, although this is standard in other countries such as Australia. Previous research in Northeast Scotland found that initial diagnostic excision biopsies in primary care that prove to be melanoma were no more likely to be incomplete than those performed in secondary care, but data on longer-term outcomes were not available.
\end{abstract}

\section{Aim}

To determine whether initial diagnostic excision biopsy of cutaneous melanoma in primary versus secondary care leads to poorer survival and increased morbidity.

\section{Design and setting}

Analysis of a linked dataset comprising pathological data from melanoma cases diagnosed in Northeast Scotland between 1991 and 2007, the General Registry Office [Scotland] death registry, and an NHS Scotland episode of care database.

\section{Method}

Patient data from three sources were matched using the Community Health Index (CHI) number. Cox proportional hazards regression, with robust standard error estimates, was used to examine the hazard ratio $195 \%$ confidence intervall) of key mortality and morbidity outcomes based on excision in primary versus secondary care. Analysis was conducted before and after adjustment for operator and patientlevel factors, using a multilevel approach.

\section{Results}

Patients receiving their initial diagnostic excision biopsy for melanoma in primary versus secondary care were no more likely to be dead, or to have died of metastatic malignant melanoma. Patients who had their initial diagnostic excision biopsy for melanoma in primary care had significantly fewer subsequent hospital admissions and spent fewer days in hospital.

\section{Conclusion}

These findings suggest that initial diagnostic excision biopsy of melanoma in primary care does not lead to poorer long-term outcomes.

\section{Keywords}

early detection of cancer; melanoma; primary health care; skin neoplasms; surgical procedures, minor.

\section{INTRODUCTION}

The incidence of melanoma continues to rise sharply in the UK. ${ }^{1}$ Current UK guidelines for the treatment of cutaneous melanoma clearly state that any skin lesion seen in primary care that could potentially be a melanoma should be referred immediately to secondary care for subsequent biopsy and further management. ${ }^{2-4}$ UK guidelines do not identify any role for GPs in the management of melanoma beyond the initial examination and referral of presenting patients. ${ }^{2-4}$ Primary care excision biopsy for diagnostic purposes is discouraged because "clinicopathological correlation is vital for diagnostic accuracy, which in turn determines prognosis and defines adjuvant treatment options and because diagnostic surgery requires specialist training.? Indeed, any patient receiving their initial diagnostic biopsy in UK primary care is commonly perceived to have been mismanaged. ${ }^{5}$ This is concerning, when it is considered that up to $20 \%$ of melanomas diagnosed in the UK have been first biopsied in primary care. ${ }^{6}$

The number of melanomas diagnosed following initial diagnostic excision biopsy in primary care is driven by two factors. First, melanoma can be difficult to diagnose and a proportion of those melanomas currently being excised in primary care have probably been incorrectly designated as benign by the doctor performing the biopsy." Secondly, many GPs perceive themselves to be skilled in minor surgery and the UK

P Murchie, BSc, MSc, PhD, MRCGP, clinical senior lecturer and GP; EA Raja, MSc, PhD research fellow in medical statistics; $\mathbf{A J}$ Lee, BSc, MSc, PhD, professor of medical statistics; NC Campbell, MA, PhD, MD, FRCP, FRCGP, reader and GP, Division of Applied Health Science, University of Aberdeen

\section{Address for correspondence}

Peter Murchie, Division of Applied Health Science, University of Aberdeen, Polwarth Building, guidelines are made in the absence of any prospective randomised comparison of the ability of specialists versus non-specialists to adequately perform initial diagnostic excision biopsies of pigmented lesions. ${ }^{2-4}$

Studies that have compared the relative abilities of primary and secondary care doctors to adequately excise pigmented lesions have varied with respect to quality and have produced contradictory findings. Four clinical audits have been conducted and reported by secondary care physicians (in East Anglia, Manchester, the Northeast Thames region, and Southeast Scotland), and have reported that GPs are more likely to perform an incomplete initial excision biopsy compared to secondary care colleagues., ${ }^{5-8-10}$ In contrast, studies from North Wales and Northeast Scotland, the latter being the only one where research was conducted blinded to location of initial excision biopsy, found quicker diagnosis and no significant difference in incomplete excision for GP versus specialist biopsy. ${ }^{6,11,12}$ To date, there have been relatively few studies that compare outcomes for patients with melanoma treated initially by different specialties; however, one study has suggested that dermatologists may achieve the best results. ${ }^{13}$ Notably, however, in Australia, which has among the highest global incidence of cutaneous melanoma, most melanomas are biopsied initially by GPs in primary care, without compromising survival compared with the UK. ${ }^{14-16}$

This study aimed to compare survival

Foresterhill, Aberdeen, AB25 2ZD.

E-mail: p.murchiedabdn.ac.uk

Submitted: 28 December 2012; Editor's response: 19 January 2013; final acceptance: 27 February 2013.

\section{CBritish Journal of General Practice}

This is the full-length article lpublished online 29 Jul 2013) of an abridged version published in print. Cite this article as: Br J Gen Pract 2013; DOI: 10.3399/bjgp13X670697 


\section{How this fits in}

Current UK guidelines do not support the initial diagnostic excision biopsy of cutaneous melanoma in primary care, despite this being standard practice in other countries such as Australia. It has previously been shown that initial diagnostic excision biopsies in primary care were no more likely to be incomplete than those performed in secondary care. This paper reports that there was no difference in all-cause or melanomaspecific mortality between those receiving their initial diagnostic excision biopsies in primary care or secondary care, and that those receiving their initial biopsy in primary care had fewer subsequent hospital admissions and attendances. Current guidelines may need to be reviewed, in order that they support the most effective model of care for people with cutaneous melanoma.

and morbidity rates between people whose cutaneous melanomas had been diagnosed following initial excision biopsy in primary versus secondary care.

\section{METHOD}

Data were linked from three datasets; the Grampian melanoma database, the General Register Office for Scotland (GRO(S)) death registry, and Scottish Morbidity Record (SMR01).

The Grampian melanoma database comprised data from 1263 individuals diagnosed with cutaneous melanoma at the Department of Pathology, Aberdeen Royal Infirmary between January 1991 and July 2007. Data included: age, sex, date of diagnosis, full name, postcode, Community Health Index (CHI) (>95\% complete), location of excision, type of skin biopsy, site of biopsy, type of melanoma, prognostic factors lulceration, vascular or lymphatic invasion, perineural invasion, regression, previous naevus), completeness of excision, requirement for second pathology opinion, Breslow depth, and Clark level.

The GRO(S) death registry provided data on date of death and primary and secondary cause of death for those individuals on the database that had subsequently died. The census date was 31 January 2010.

SMR01 is an episode-based record relating to all inpatient and day cases discharged from Scottish hospitals. ${ }^{17}$ The quality of the database has been assured on several occasions. ${ }^{17,18}$ Data were abstracted on the inpatient and day case attendances (including outpatient attendances) of all database subjects from 1991 until 31 January 2010.

\section{Data linkage}

These databases were linked using the $\mathrm{CHI}$ number, which was available for 1229 (97.3\%) of the 1263 patients. The $\mathrm{CHI}$ number is a unique identifying number from a centrally maintained register called the Community Health Index (CHI), which is issued to every person registered with a GP in Scotland. ${ }^{19}$ The $\mathrm{CHI}$ number is the unique patient identifier in all primary healthcare activities, and is now used in hospital-based clinical information systems, achieving $93 \%$ compliance. It is the key to linking health data for research purposes. The $\mathrm{CHI}$ register contains data on address, postcode, GP, date and region of registration, and, where relevant, date of death, allowing the demographic profile of Scotland, death, and patient migration to be easily described.

In the small number of cases where the $\mathrm{CHI}$ number was unavailable, SMR01 and death records were linked using computerised probability linkage, where personally identified information from the three sources was compared in order to match up individuals. ${ }^{20}$ Such linkage has a high level of accuracy, with false-positive and false-negative rates of about $1 \%{ }^{19}$

\section{Main outcomes}

1. All-cause survival from date of melanoma diagnosis. Date of diagnosis corresponded with date of issue of the pathology report, which was available for all cases.

2. Cause-specific survival from the date of diagnosis.

3. The relative proportion of cases where recurrent melanoma is a listed cause of death.

4. The total number of inpatient visits and total number of days spent in hospital from the date of melanoma diagnosis.

5. The number of inpatient visits and total number of days spent in hospital, by specialty, from the date of melanoma diagnosis.

6. The total number of outpatient attendances from the date of melanoma diagnosis.

7. The number of outpatient attendances, by specialty, from the date of melanoma diagnosis.

\section{Main predictor}

Location of initial diagnostic excision biopsy (primary or secondary care). 


\section{Potential confounders}

Patient-level confounders. Age, sex residence category (based on postcode and the Scottish Government six-fold Rural/ Urban Classification), ${ }^{21}$ deprivation (using the Scottish Index of Multiple Deprivation (SIMD), ${ }^{22}$ type of biopsy, anatomical site of biopsy, type of melanoma, prognostic factors lulceration, vascular or lymphatic invasion, perineural invasion, regression, previous naevus), completeness of excision, requirement for a second pathology opinion, Breslow depth la prognostic feature based on the depth in millimetres by which a melanoma has invaded the dermis of the skin, ${ }^{4}$ and Clark level la staging system related to Breslow depth, where the depth of melanoma invasion is related to the anatomical features of the skin). ${ }^{4}$

Operator-level confounders. In the primary analysis, location of initial diagnostic excision biopsy was the only operator-level variable. A secondary analysis used specialty of operator (plastic surgeon, dermatologist, other hospital specialist, GP frequent exciser who excised $\geq 5$ melanomas during the study period, GP) as the main predictor of mortality and morbidity land excluded location of initial diagnostic excision biopsy, since the two operator-level factors are obviously interrelated).

\section{Statistical analysis}

Two specific hypotheses were examined:

1. Patients with melanoma receiving their initial diagnostic excision biopsy in primary care would have poorer survival than those receiving their initial diagnostic excision biopsy in secondary care.

2. Patients with melanoma receiving their initial diagnostic excision biopsy in primary care would have greater morbidity than those receiving their initial diagnostic excision biopsy in secondary care.

The data had a multilevel structure, with patients nested within operators. The patients diagnosed following either initial diagnostic excision biopsy in either primary or secondary care were followed until death, date of emigration, loss to follow-up, or 31 January 2012, whichever occurred first. Univariate Cox regression analysis was used to explore the association between patient- and operator-level factors and all-cause mortality. Cox proportional hazards regression, with robust standard error estimates, was used to examine the hazard ratio (95\% confidence interval [CI]) of initial diagnostic excision biopsy in primary versus secondary care, before and after adjustment for operator- and patient-level factors, using a multilevel approach. ${ }^{23}$

To explore morbidity, the number and duration of admissions and outpatient attendances loverall and within individual specialtyl were calculated for each patient following diagnosis. Initial univariate analysis of total admissions and outpatient attendances by location of initial diagnostic excision biopsy was conducted using the Mann-Whitney U test. Generalised linear models with a Poisson distribution and log link function were used for count morbidity factors, a binomial distribution and log link function for binary morbidity factors, and a Gaussian distribution and identity link function for continuous morbidity measures. The models were used to examine the association between morbidity and location of initial diagnostic excision biopsy before and after adjustment for operator- and patient-level factors. Multinomial logistic regression was used to explore the association between categorical morbidity factors and the location of initial diagnostic excision biopsy. Potential confounders were those that showed a significant association with location of initial diagnostic excision biopsy using a generalised linear model.

The multilevel models for morbidity and mortality were then repeated using specialty of operator as the main predictor (secondary models). This was because a small number $(n=12)$ of the melanomas excised in primary care had been removed by secondary care specialists at an outreach clinic in a large practice. Additionally, 28 of the secondary care melanomas had been excised by GPs or GP frequent excisers at secondary care clinics. The secondary analysis was conducted to determine the importance of this small amount of crossover. All analyses were carried out under a multilevel model framework, using STATA version 12. A $P$-value of $\leq 0.05$ was considered statistically significant throughout.

\section{Statistical power}

There were 1263 patients with cutaneous melanoma, of whom 262 had their initial diagnostic excision biopsy in primary care, with 1001 receiving their biopsy in secondary care. In the age group 15-99 years, the observed 10-year survival for people diagnosed with melanoma between 1998 and 2002 was $67.3 \% .{ }^{24}$ Therefore, in the study sample, if there was no difference in mortality by location of initial diagnostic 
excision biopsy, after 10 years of followup, 178 survivors and 84 deaths would be expected in the primary-care excision group, and 681 survivors and 320 deaths in the secondary-care excision group. Based on these figures, there was $89 \%$ power to detect a $10 \%$ difference in mortality between the primary and secondary care groups at the two-sided 5\% significance level.

\section{RESULTS}

\section{Demographics and clinical details}

Tables 1 and 2 summarise the demographic characteristics of the patients in the sample and the clinical characteristics of the excised melanomas. A total of 262 (20.7\%) melanomas were excised in

\section{Table 1. Demographics of sample, anatomical site of biopsy, specialty seen, and type of biopsy by setting}

\begin{tabular}{|c|c|c|c|}
\hline & Primary care biopsy & Secondary care biopsy & $P$-value \\
\hline Overall $n$ & 262 & 1001 & \\
\hline Age, mean years (SD) & $51.8(17.1)$ & $59.4(18.3)$ & $<0.001$ \\
\hline Sex, male, $n(\%)$ & 103 (39.3) & $417(41.7)$ & 0.415 \\
\hline \multicolumn{4}{|l|}{ Place of residence, $n(\%)$} \\
\hline Large urban area & $54(20.6)$ & $381(38.1)$ & 0.087 \\
\hline Other urban area & $45(17.2)$ & 132 (13.2) & \\
\hline Accessible small town & $16(6.1)$ & $74(7.4)$ & \\
\hline Remote small town & 30 (11.5) & 87 (8.7) & \\
\hline Accessible rural & $66(25.2)$ & $190(19.0)$ & \\
\hline Remote rural & $49(18.7)$ & $132(13.2)$ & \\
\hline 2009 SIMD quintile, $n$ (\%) & & & $<0.001$ \\
\hline 1 most deprived & $2(0.8)$ & $39(3.9)$ & \\
\hline 2 & $13(5.0)$ & 123 (12.3) & \\
\hline 3 & $44(16.9)$ & 233 (23.4) & \\
\hline 4 & $100(38.5)$ & 247 (24.8) & \\
\hline 5 least deprived & 101 (38.8) & 354 (35.5) & \\
\hline \multicolumn{4}{|l|}{ Anatomical site, $n(\%)$} \\
\hline Head and neck & 32 (12.9) & $260(27.1)$ & \\
\hline Body & $72(29.0)$ & 225 (23.4) & \\
\hline Upper limb & $61(24.6)$ & 133 (13.9) & \\
\hline Groins & $0(-)$ & $23(2.4)$ & \\
\hline Lower limbs & 83 (33.5) & 319 (33.2) & \\
\hline Site unknown & 14 & 41 & \\
\hline Specialty, $n[\%]$ & & & $<0.001$ \\
\hline $\mathrm{GP}$ & 157 (59.9) & $6(0.6)$ & \\
\hline GP frequent exciser ${ }^{a}$ & 93 (35.5) & $22(2.2)$ & \\
\hline Plastic surgeon & $10(3.8)$ & $512(51.1)$ & \\
\hline Dermatologist & $0(-)$ & 152 (15.2) & \\
\hline General surgeon & $2(0.8)$ & 218 (21.8) & \\
\hline Other hospital specialists & $0(-)$ & $91(9.1)$ & \\
\hline Type of biopsy, $n(\%)$ & & & 0.138 \\
\hline Excisional & 245 (93.5) & 895 (89.4) & \\
\hline Incisional & $2(0.8)$ & $41(4.1)$ & \\
\hline Punch biopsy & $7(2.7)$ & $45(4.5)$ & \\
\hline Total otherb & $8(3.1)$ & $20(2.0)$ & \\
\hline
\end{tabular}

$S D=$ standard deviation. $S I M D=$ Scottish Index of Multiple Deprivation. ${ }^{a} G P S$ who excised $\geq 5$ melanomas during the study period. ${ }^{b}$ Comprises curettage, shave, operative, enucleation, and amputation. primary care, and these patients were significantly younger $(P<0.001)$ and less deprived $(P<0.001)$ than those in secondary care. Melanomas excised in primary care were more likely to be from the upper limb and body, and less likely to be on the head and neck $(P<0.001)$. There were no significant differences between primary and secondary care excision in terms of sex $(P=0.415)$, place of residence $(P=0.087)$, or type of biopsy. As expected, primary care excisions tended to be performed by GPS and secondary care excisions by hospital specialists $(P<0.001)$. Table 2 shows that there was no significant difference between primary and secondary care biopsies in the proportion being reported as complete ( $P=0.740)$, but that significantly more of those biopsies performed in primary care were forwarded for a second opinion by the referring pathologist $(P<0.001)$. There was no significant difference in Breslow thickness between lesions excised in primary versus secondary care $(P=0.104)$, but those excised in primary care had a significantly lower Clark level $(P<0.024)$.

\section{Mortality}

A total of $57(21.7 \%)$ of those having their melanoma excised in primary care died during follow-up, compared with 395 $(39.4 \%)$ of those having their melanoma excised in secondary care $(P<0.001)$. Similarly, median survival was 62.6 months (interquartile range $[I Q R]=31.1$ to 99.4 months) in the primary care group versus 46.3 months (IQR $=21.6$ to 89.6 months) in the secondary care group $(P=0.034)$. Twenty-seven $(47.4 \%)$ of the deaths in the primary care group were due to metastatic melanoma, compared with 149 (37.7\%) of the deaths in the secondary care group $(P=0.401)$. Figure 1 displays a Cox regression survival curve illustrating the unadjusted differences in survival between patients in primary and secondary care.

Table 3 shows the results of multilevel modelling of all-cause mortality and melanoma-related mortality. Following adjustment for important confounders, the difference in survival between those having their initial diagnostic excision biopsy in primary care was not significantly different from that for those having their initial diagnostic excision biopsy excision in secondary care. This was true for both all-cause mortality (hazard ratio $=0.87,95 \%$ $\mathrm{Cl}=0.66$ to 1.14 ) and melanoma-related mortality (hazard ratio $=0.95,95 \% \mathrm{Cl}=0.57$ to 1.61). For all-cause mortality, the specialty of the operator was not significantly associated with risk of death. For cause of 
Table 2. Outcome of biopsy and prognostic features of biopsy by place of excision

\begin{tabular}{|c|c|c|c|}
\hline & $\begin{array}{c}\text { Primary care, } \\
\quad n=262\end{array}$ & $\begin{array}{c}\text { Secondary care, } \\
\qquad n=1001\end{array}$ & $P$-value \\
\hline \multicolumn{4}{|l|}{ Completeness of excision, $n[\%]$} \\
\hline Completely excised & $190(72.5)$ & 698 (69.7) & 0.740 \\
\hline Incompletely excised & $52(19.8)$ & 227 (22.7) & \\
\hline Not stated & $20(7.6)$ & $76(7.6)$ & \\
\hline \multicolumn{4}{|l|}{ Second pathology opinion, $n(\%)$} \\
\hline Referred & $29(11.1)$ & $71(7.1)$ & $<0.001$ \\
\hline Not referred & 233 (88.9) & 929 (92.9) & \\
\hline \multicolumn{4}{|l|}{ Ulceration, $n[\%]$} \\
\hline Present & 30 (11.5) & $151(15.1)$ & 0.330 \\
\hline Absent & 48 (18.3) & $169(16.9)$ & \\
\hline Not reported & $184(70.2)$ & $681(68.0)$ & \\
\hline \multicolumn{4}{|l|}{ Lymphatic/vascular invasion, $n(\%)$} \\
\hline Present & $1(0.4)$ & $30(3.0)$ & 0.119 \\
\hline Absent & $65(24.8)$ & $241(24.1)$ & \\
\hline Not reported & $196(74.8)$ & $730(72.9)$ & \\
\hline \multicolumn{4}{|l|}{ Perineural invasion, $n[\%]$} \\
\hline Present & $1(0.4)$ & $6(0.6)$ & 0.675 \\
\hline Absent & $13(5.0)$ & $40(4.0)$ & \\
\hline Not reported & $248(94.7)$ & 955 (95.4) & \\
\hline \multicolumn{4}{|l|}{ Regression, $n$ (\%) } \\
\hline Present & $17(6.5)$ & 118 (11.8) & 0.043 \\
\hline Absent & $43(16.4)$ & $146(14.6)$ & \\
\hline Not reported & $202(77.1)$ & $737(73.6)$ & \\
\hline \multicolumn{4}{|l|}{ Previous intradermal naevus, $n[\%]$} \\
\hline Present & $23(8.8)$ & 107 (10.7) & 0.527 \\
\hline Absent & 34 (13.0) & 110 (11.0) & \\
\hline Not reported & 205 (78.2) & 784 (78.3) & \\
\hline \multicolumn{4}{|l|}{ Clark level, $n(\%)$} \\
\hline । & 40 (15.3) & $118(11.8)$ & 0.024 \\
\hline$\|$ & $41(15.6)$ & $145(14.5)$ & \\
\hline III & $66(25.2)$ & $222(22.2)$ & \\
\hline IV & $74(28.2)$ & 253 (25.3) & \\
\hline V & $5(1.9)$ & $46(4.6)$ & \\
\hline Not stated & $36(13.7)$ & $243(24.3)$ & \\
\hline Breslow thickness, mm, median (IQR) & 0.9 (0.4 to 1.85$)$ & 1.0 (0.4 to 2.3$)$ & 0.104 \\
\hline
\end{tabular}

death from metastatic melanoma, however, those having their melanoma excised by 'another specialist' were at significantly lower risk of melanoma-related mortality (hazard ratio $=0.46,95 \% \mathrm{Cl}=0.22$ to 0.93 ), perhaps reflecting a tendency for these to be incidental findings of relatively early melanoma during care for other conditions.

\section{Morbidity}

Table 4 summarises the univariate analysis of morbidity outcomes using the MannWhitney $U$ test. The median (IQR) total, emergency, elective, melanoma-specific, skin cancer, and non-cancer admissions for both groups are shown. All medians were significantly lower in the primary care versus secondary care group (all $P<0.05$ ) Those receiving their initial diagnostic excision biopsy in primary care spent significantly fewer days in hospital than those having their initial diagnostic excision biopsy in secondary care $(P<0.001)$. There were no significant differences between the two groups in total outpatient attendances, although patients in the primary care group were seen more often in medical oncology and dermatology compared to the secondary care group.

Table 5 shows the multilevel Poisson regression for morbidity outcomes. Those receiving their initial diagnostic excision biopsy in primary care had significantly fewer total hospital admissions (hazard ratio $=0.76,95 \% \mathrm{Cl}=0.63$ to 0.92 ), spent fewer days in hospital (hazard ratio $=0.75$, $95 \% \mathrm{Cl}=0.61$ to 0.93 ), and had fewer outpatient attendances (hazard ratio $=0.95$, $95 \% \mathrm{Cl}=0.84$ to 1.08 ) than those receiving their initial diagnostic excision biopsy in secondary care, although the difference in outpatient attendances is non-significant.

\section{DISCUSSION \\ Summary}

This study found no significant difference in survival for patients who received their initial diagnostic excision biopsy for melanoma in primary versus secondary care. Further, it has shown that patients receiving their initial diagnostic excision biopsy in primary versus secondary care are not more likely to die from melanoma. Patients who received their initial diagnostic excision biopsy for melanoma in primary care had significantly fewer subsequent hospital admissions, spent fewer days in hospital, and had fewer outpatient attendances than those receiving their initial diagnostic excision biopsy in primary care. Together, these findings suggest that having an initial diagnostic excision biopsy in primary care does not lead to poorer long-term outcomes.

\section{Strengths and limitations}

The study was based on comprehensive data from a relatively large cohort of patients from a large geographical area in northern Scotland. This has ensured a wide range of age, sex, place of residence, and relative affluence, suggesting that the results are likely to be generalisable, at least within Scotland. Furthermore, the period of time during which the original data were collected includes the period after the introduction of the current guidelines for the urgent referral of suspected cancer, so that the data represent current practice. Community Health Index numbers were available for almost all of the patients in the original cohort, meaning that there are 
Table 3. Multilevel model of all-cause mortality and melanoma-specific mortality: reduced model based on the significance of factors in the first multivariate model

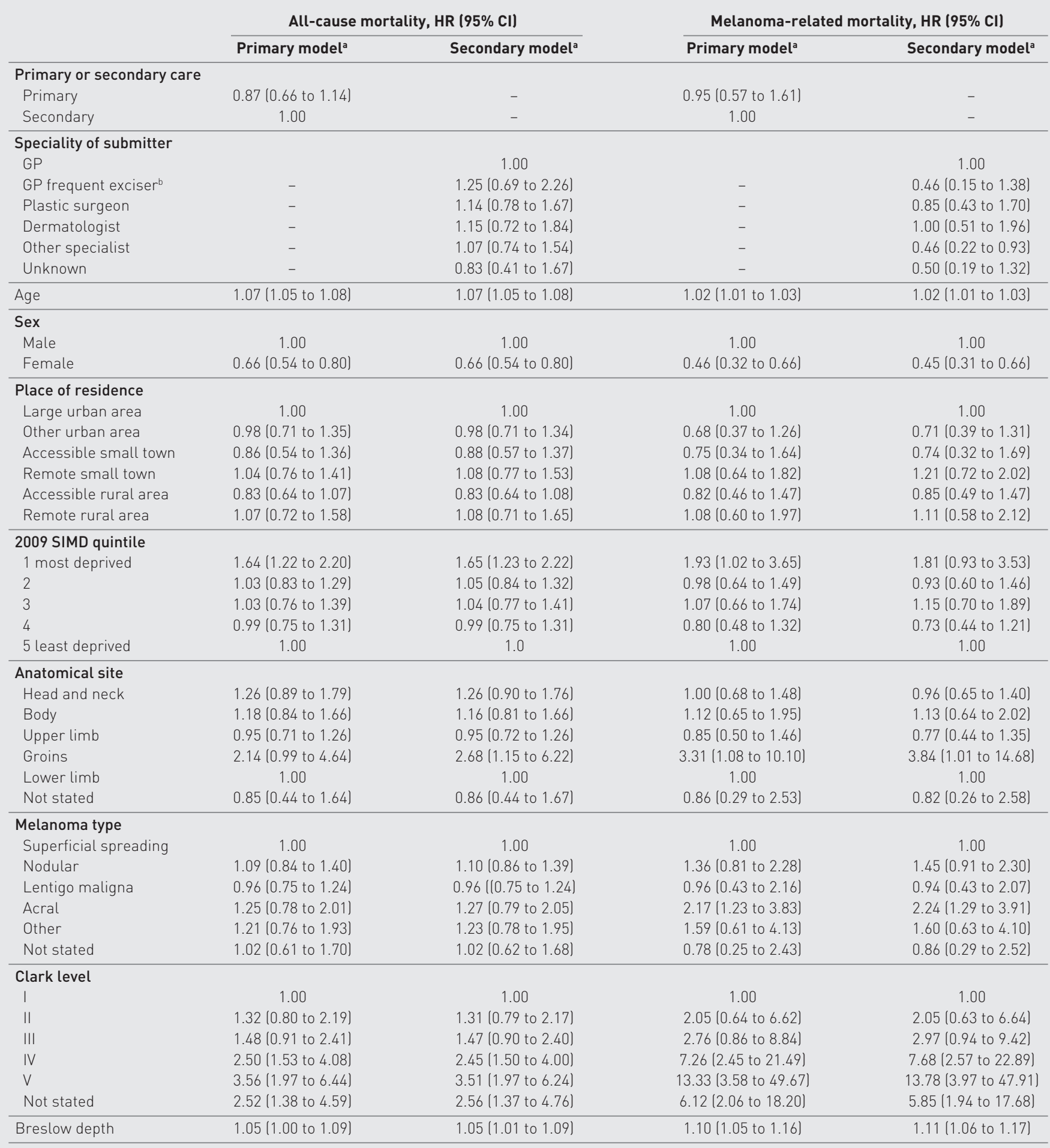

SIMD = Scottish Index of Multiple Deprivation. ${ }^{a}$ The primary model used location of excision as the primary predictor, while the secondary model used the specialty of the submitter as the primary predictor. ${ }^{b} G$ Ps who excised $\geq 5$ melanomas during the study period.

practically no missing data for the most important outcomes.

This was a retrospective observational study and not a randomised comparison.
GPs perhaps tend to remove more straightforward lesions, thereby biasing the data in their favour, but the adjusted analysis has taken account of the biopsy site and type. 


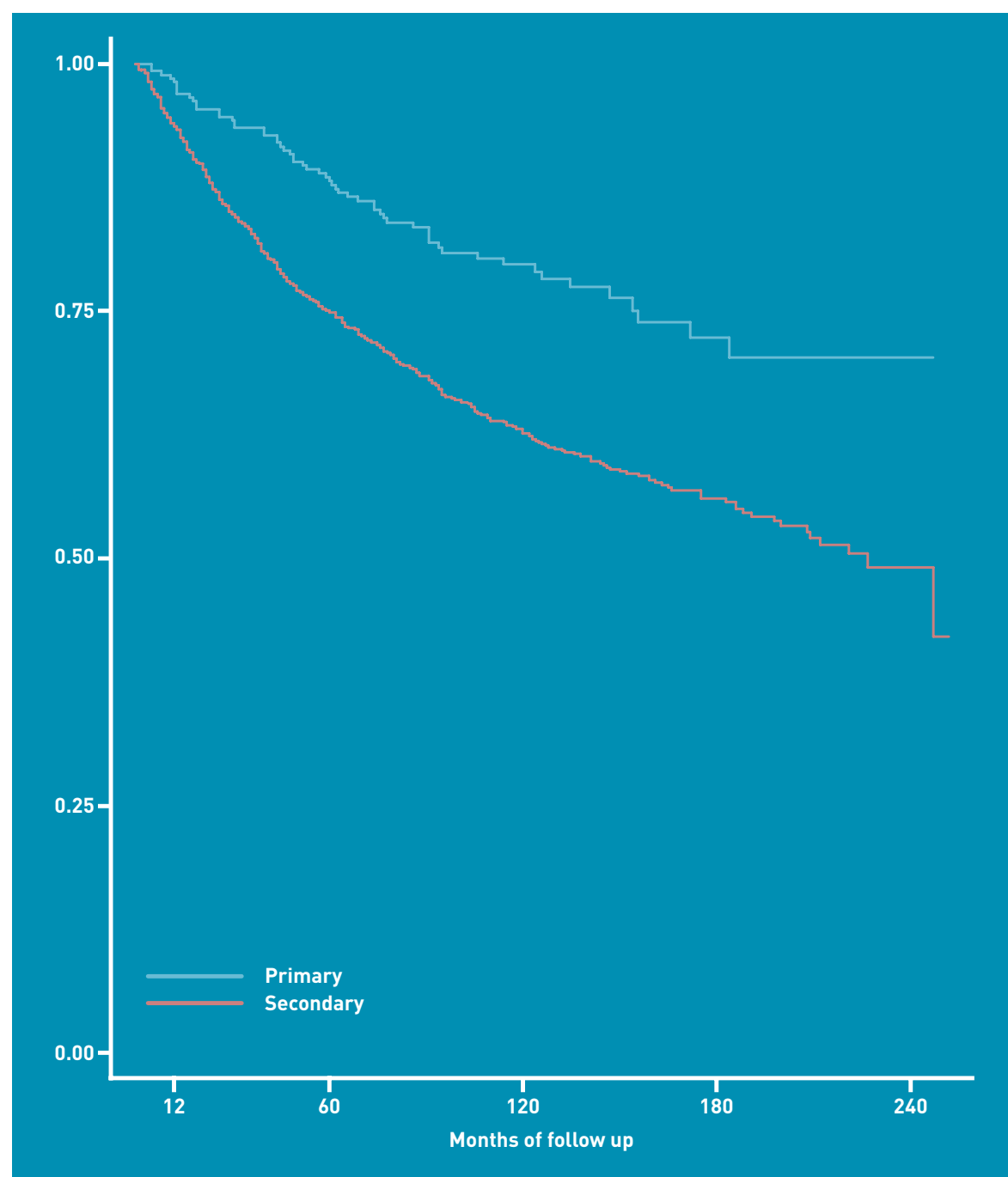

Figure 1. Cox survival curve for those receiving initial diagnostic excision biopsy in primary versus secondary care. Univariate hazard ratio $=1.99(95 \% \mathrm{Cl}=1.50$ to 2.62$)$.

\section{Table 4. Median (interquartile range) number of inpatient admissions, inpatient bed-days, and outpatient attendances by setting}

\begin{tabular}{lccc} 
& Primary care biopsy & Secondary care biopsy & $\boldsymbol{P}_{\text {-value }}$ \\
\hline Impatient admissions & $2(1$ to 5$)$ & $3(1$ to 7$)$ & $<0.001$ \\
Total admissions & $0(0$ to 1$)$ & $1(0$ to 3$)$ & $<0.001$ \\
Emergency admissions & $1(1$ to 3$)$ & $2(1$ to 4$)$ & 0.006 \\
Elective admissions & $0(0$ to 1$)$ & $1(0$ to 1$)$ & $<0.001$ \\
Melanoma admissions & $0(0$ to 0$)$ & $0(0$ to 0$)$ & 0.813 \\
Metastases admissions & $0(0$ to 0$)$ & $0(0$ to 0$)$ & 0.019 \\
Skin cancer admissions & $0(0$ to 0$)$ & $0(0$ to 0$)$ & 0.086 \\
Other cancer admissions & $1(0$ to 3$)$ & $2(0$ to 4.5$)$ & 0.004 \\
Non-cancer admissions & $5(1$ to 21$)$ & $14(3$ to 44$)$ & $<0.001$ \\
Total inpatient bed-days & $15(7$ to 26$)$ & $16(7$ to 28$)$ & 0.231 \\
\hline Outpatient attendances & $0(0$ to 0$)$ & $0(0$ to 0$)$ & 0.159 \\
Total attendances & $7(0$ to 13$)$ & $3(0$ to 11$)$ & 0.062 \\
Attendance to dermatology & $0(0$ to 0$)$ & $0(0$ to 0$)$ & 0.534 \\
Medical oncology & $0(0$ to 0$)$ & $0(0$ to 0$)$ & 0.184 \\
Palliative medicine & $2(0$ to 4.25$)$ & $2(0$ to 3$)$ & 0.414 \\
General surgery & & & \\
Plastic surgery & &
\end{tabular}

aMann-Whitney $U$ test.
In contrast, GPs could be referring the more obviously malignant lesions and removing those with an atypical appearance, which may represent less aggressive tumours. There was no way of establishing what grade of specialist had excised melanomas in hospital, potentially biasing the results against consultants. On the other hand, it is likely that this reflects current practice within secondary care. The data presented are from the Grampian region only, so it is not clear if these results apply more widely. There is no logical reason, however, at least in Scotland, to believe that things would be any different elsewhere. Finally, no data were available on comorbidities, and consequently it was not possible to adjust for them in the multivariate analysis. The fact that those receiving their initial excisions in primary care were younger could mean that they were fitter and less likely to require any type of subsequent hospital treatment, thereby exaggerating the differences between the primary and secondary care groups. Nevertheless, these differences remained despite adjustments for age and specific classes of admission and hospital outpatient attendance. Hospital admissions and outpatient attendances were used as a proxy for a patient's postoperative morbidity. This was felt to be justified, since, logically, the sickest patients should spend more time in hospital and at outpatient clinics. On the other hand, there are non-clinical factors that could be influential here, such as the relative willingness of different healthcare professionals to discharge patients from follow-up, and the analysis cannot control for this. Finally, a number of statistical comparisons were made, and, as always with this type of research, it is possible that some of the significant findings are due to chance.

\section{Comparison with existing literature}

Studies that have compared the relative abilities of doctors in primary and secondary care to adequately excise pigmented lesions have varied with respect to quality and have produced contradictory findings, with four audits from the UK conducted in secondary care suggesting that incomplete diagnostic excision biopsies of melanoma are significantly more likely when conducted by GPs., ${ }^{5,-10}$ On the other hand, studies employing larger series and where the risk of bias has been minimised by blinding the location of excision biopsy during quality rating, have found no significant difference. 6,12,13

Previous research has explored the relationship between who excises melanoma 
Table 5. Multilevel Poisson regression analysis to identify factors independently associated with morbidity outcomes: reduced model based on the significance of factors in the first multivariate model

\begin{tabular}{|c|c|c|c|c|c|c|}
\hline \multirow{4}{*}{$\begin{array}{l}\text { Location of biopsy } \\
\text { Primary care }\end{array}$} & \multicolumn{2}{|c|}{ Admissions, RR (95\% Cl) } & \multicolumn{2}{|c|}{ Number of bed days, RR ( $95 \% \mathrm{Cl})$} & \multicolumn{2}{|c|}{ Outpatient attendances, RR (95\% Cl) } \\
\hline & \multirow{2}{*}{ Primary model $^{\mathrm{a}}$} & \multirow[t]{2}{*}{ Secondary modela } & \multirow[t]{2}{*}{ Primary model $^{\mathrm{a}}$} & \multirow[t]{2}{*}{ Secondary model ${ }^{\mathrm{a}}$} & \multirow[t]{2}{*}{ Primary model $^{\mathrm{a}}$} & \multirow[t]{2}{*}{ Secondary model ${ }^{\mathrm{a}}$} \\
\hline & & & & & & \\
\hline & 0.76 (0.63 to 0.92 ) & - & 0.75 (0.61 to 0.93 ) & - & 0.95 (0.84 to 1.08 ) & - \\
\hline Secondary care & 1.00 & - & 1.00 & - & 1.00 & - \\
\hline \multicolumn{7}{|l|}{ Speciality of submitter } \\
\hline GP & & 1.00 & & 1.00 & & 1.00 \\
\hline GP frequent exciser ${ }^{b}$ & - & 0.96 (0.75 to 1.22$)$ & - & 1.12 (0.78 to 1.62$)$ & - & 1.12 (0.78 to 1.62 ) \\
\hline Plastic surgeon & - & $1.23(0.96$ to 1.56$)$ & - & 1.24 (0.92 to 1.66$)$ & - & $1.24(0.92$ to 1.66$)$ \\
\hline Dermatologist & - & 1.12 (0.81 to 1.55$)$ & - & 1.27 (0.69 to 2.35$)$ & - & 1.27 (0.69 to 2.35$)$ \\
\hline Other specialist & - & 1.51 (1.19 to 1.92 ) & - & 1.55 (1.14 to 2.10$)$ & - & 1.55 (1.14 to 2.10$)$ \\
\hline Unknown & - & 1.68 (1.22 to 2.31$)$ & - & 1.50 (1.04 to 2.16$)$ & - & 1.50 (1.04 to 2.16$)$ \\
\hline Age & 1.01 (1.01 to 1.02) & 1.01 (1.01 to 1.02$)$ & 1.04 (1.03 to 1.04$)$ & 1.04 (1.03 to 1.04$)$ & 1.00 (0.99 to 1.00$)$ & 1.04 (1.03 to 1.04$)$ \\
\hline \multicolumn{7}{|l|}{ Sex } \\
\hline Male & 1.00 & 1.00 & 1.00 & 1.00 & 1.00 & 1.00 \\
\hline Female & 0.95 (0.85 to 1.06$)$ & 0.95 (0.85 to 1.06$)$ & 1.15 (0.97 to 1.36$)$ & 1.15 (0.96 to 1.38$)$ & 1.08 (0.97 to 1.21$)$ & 1.15 (0.96 to 1.38 ) \\
\hline \multicolumn{7}{|l|}{ Place of residence } \\
\hline Large urban area & 1.00 & 1.00 & 1.00 & 1.00 & 1.00 & 1.00 \\
\hline Other urban area & 1.24 (1.00 to 1.52$)$ & 1.24 (1.01 to 1.52 ) & 1.09 (0.90 to 1.33 ) & 1.09 (0.89 to 1.34 ) & 0.87 (0.75 to 0.99 ) & 1.09 (0.89 to 1.34 ) \\
\hline Accessible small town & 0.76 (0.62 to 0.93 ) & 0.74 (0.61 to 0.90 ) & 0.79 (0.59 to 1.05 ) & 0.78 (0.59 to 1.03 ) & 0.76 (0.66 to 0.88 ) & 0.78 (0.59 to 1.03 ) \\
\hline Remote small town & 1.23 (0.97 to 1.55$)$ & 1.18 (0.93 to 1.50$)$ & 1.14 (0.89 to 1.47 ) & 1.12 (0.86 to 1.46 ) & 0.87 (0.69 to 1.11 ) & 1.12 (0.86 to 1.46 ) \\
\hline Accessible rural area & 0.94 (0.79 to 1.13 ) & 0.93 (0.78 to 1.11 ) & 0.96 (0.76 to 1.21$)$ & 0.95 (0.74 to 1.22 ) & 0.88 (0.79 to 0.98 ) & 0.95 (0.74 to 1.22 ) \\
\hline Remote rural area & 0.95 (0.80 to 1.14 ) & 0.91 (0.75 to 1.09 ) & 0.89 (0.69 to 1.16 ) & 0.85 (0.65 to 1.11$)$ & 0.65 (0.55 to 0.77$)$ & 0.85 (0.65 to 1.11$)$ \\
\hline \multicolumn{7}{|l|}{2009 SIMD quintile } \\
\hline 1 most deprived & 0.93 (0.63 to 1.39 ) & 0.95 (0.66 to 1.39 ) & 1.01 (0.70 to 1.48 ) & 1.06 (0.74 to 1.51$)$ & 0.96 (0.70 to 1.32 ) & $1.06(0.74$ to 1.51$)$ \\
\hline 2 & 1.01 (0.84 to 1.20$)$ & $1.01(0.84$ to 1.21$)$ & $1.14(0.92$ to 1.40$)$ & 1.15 (0.93 to 1.42 ) & 1.10 (0.92 to 1.31$)$ & 1.15 (0.93 to 1.42 ) \\
\hline 3 & 1.03 (0.89 to 1.19 ) & 1.01 (0.87 to 1.17 ) & 1.08 (0.80 to 1.45$)$ & 1.07 (0.79 to 1.46$)$ & 0.96 (0.84 to 1.10$)$ & 1.07 (0.79 to 1.46$)$ \\
\hline 4 & 0.93 (0.77 to 1.12 ) & $0.92(0.76$ to 1.12$)$ & 1.12 (0.84 to 1.50$)$ & 1.13 (0.84 to 1.52$)$ & 0.94 (0.83 to 1.07 ) & 1.13 (0.84 to 1.52$)$ \\
\hline 5 least deprived & 1.00 & 1.00 & 1.00 & 1.00 & 1.00 & 1.00 \\
\hline \multicolumn{7}{|l|}{ Anatomical site } \\
\hline Head and neck & 1.01 (0.82 to 1.23 ) & 1.01 (0.83 to 1.23 ) & 1.15 (0.91 to 1.47 ) & 1.16 (0.91 to 1.49$)$ & 0.98 (0.81 to 1.18 ) & 1.16 (0.91 to 1.49$)$ \\
\hline Body & 1.04 (0.77 to 1.41$)$ & 1.04 (0.77 to 1.40 ) & 0.93 (0.65 to 1.35$)$ & 0.92 (0.64 to 1.33 ) & 0.92 (0.77 to 1.09 ) & 0.92 (0.64 to 1.33 ) \\
\hline Upper limb & 1.01 (0.86 to 1.20 ) & 1.00 (0.85 to 1.18$)$ & $0.91(0.72$ to 1.16$)$ & 0.91 (0.72 to 1.15$)$ & 0.97 (0.87 to 1.09 ) & 0.91 (0.72 to 1.15$)$ \\
\hline Groin & 1.00 (0.70 to 1.44$)$ & 0.86 (0.57 to 1.28 ) & 1.07 (0.75 to 1.52 ) & 0.98 (0.65 to 1.50 ) & 0.67 (0.44 to 1.04$)$ & 0.98 (0.65 to 1.50$)$ \\
\hline Lower limb & 1.00 & 1.00 & 1.00 & 1.00 & 1.00 & 1.00 \\
\hline Not stated & 0.78 (0.51 to 1.17 ) & 0.73 (0.47 to 1.13 ) & 0.69 (0.47 to 1.01 ) & 0.65 (0.44 to 0.97 ) & 0.94 (0.74 to 1.18 ) & 0.65 (0.44 to 0.97 ) \\
\hline \multicolumn{7}{|l|}{ Melanoma type } \\
\hline Superficial spreading & 1.00 & 1.00 & 1.00 & 1.00 & 1.00 & 1.00 \\
\hline Nodular & 0.90 (0.70 to 1.16$)$ & 0.89 (0.70 to 1.14 ) & 0.94 (0.71 to 1.24 ) & 0.93 (0.71 to 1.22 ) & 1.03 (0.86 to 1.23 ) & 0.93 (0.71 to 1.22 ) \\
\hline Lentigo maligna & 0.87 (0.71 to 1.06 ) & 0.87 (0.72 to 1.05 ) & 0.94 (0.69 to 1.29 ) & 0.95 (0.70 to 1.28$)$ & 0.87 (0.68 to 1.12 ) & 0.95 (0.70 to 1.28$)$ \\
\hline Acral & 1.03 (0.78 to 1.36 ) & 1.01 (0.76 to 1.35 ) & 1.20 (0.79 to 1.82 ) & 1.19 (0.79 to 1.79$)$ & 0.96 (0.75 to 1.24 ) & 1.19 (0.79 to 1.79$)$ \\
\hline Other & 0.98 (0.78 to 1.24$)$ & $0.97(0.78$ to 1.21$)$ & $1.11(0.83$ to 1.49$)$ & 1.09 (0.81 to 1.46$)$ & 1.19 (0.99 to 1.43 ) & 1.09 (0.81 to 1.46$)$ \\
\hline Not stated & 0.78 (0.59 to 1.04 ) & 0.79 (0.59 to 1.05 ) & $0.83(0.56$ to 1.25$)$ & 0.83 (0.56 to 1.24 ) & 0.90 (0.72 to 1.12 ) & 0.83 (0.56 to 1.24 ) \\
\hline \multicolumn{7}{|l|}{ Clark level } \\
\hline 1 & 1.00 & 1.00 & 1.00 & 1.00 & 1.00 & 1.00 \\
\hline$\|$ & 0.92 (0.72 to 1.17 ) & 0.93 (0.73 to 1.18 ) & 1.00 (0.69 to 1.45 ) & 1.01 (0.70 to 1.47 ) & 1.18 (0.91 to 1.52 ) & 1.01 (0.70 to 1.47$)$ \\
\hline III & 1.34 (1.11 to 1.62$)$ & 1.34 (1.10 to 1.63$)$ & 1.26 (0.83 to 1.92$)$ & 1.26 (0.81 to 1.96$)$ & $1.42(1.12$ to 1.80$)$ & 1.26 (0.81 to 1.96$)$ \\
\hline IV & 1.37 (1.07 to 1.75$)$ & 1.37 (1.06 to 1.77$)$ & 1.42 (0.96 to 2.10 ) & 1.43 (0.95 to 2.15$)$ & 1.48 (1.12 to 1.95$)$ & 1.43 (0.95 to 2.15$)$ \\
\hline V & 1.20 (0.94 to 1.53 ) & 1.24 (0.98 to 1.58 ) & 0.86 (0.60 to 1.24$)$ & 0.91 (0.62 to 1.34$)$ & 1.51 (1.12 to 2.03 ) & 0.91 (0.62 to 1.34$)$ \\
\hline Not stated & 0.89 (0.73 to 1.09 ) & 0.91 (0.74 to 1.11$)$ & 0.88 (0.58 to 1.33 ) & 0.90 (0.59 to 1.38 ) & 1.13 (0.87 to 1.49 ) & 0.90 (0.59 to 1.38 ) \\
\hline Breslow depth & 1.00 (0.98 to 1.02 ) & 1.00 (0.98 to 1.01$)$ & 1.01 (0.99 to 1.03) & 1.01 (0.99 to 1.02 ) & 1.00 (0.97 to 1.04$)$ & 1.01 (0.99 to 1.02 ) \\
\hline
\end{tabular}

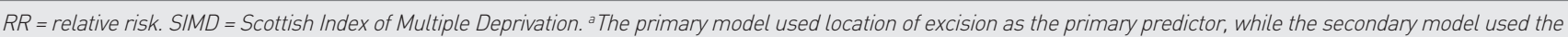
specialty of the submitter as the primary predictor. ${ }^{b} G P s$ who excised $\geq 5$ melanomas during the study period.

and survival. In 2002, Mackie et al reported data from the Scottish Melanoma Register on 4159 people diagnosed with cutaneous melanoma in Scotland between 1979 and
$1998 .{ }^{25}$ The authors compared survival by the training background (dermatologist, plastic surgeon, or general surgeon) of the operators who had removed at least 


\section{Funding}

The study was funded by the Chief Scientist Office of the Scottish Government, reference

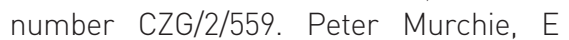
Amalraj Raja and Amanda J Lee are all employed by the University of Aberdeen, which acted as a sponsor for the study.

\section{Ethical approval}

This was a clinical audit of anonymised data. Ethical approval was not required.

\section{Provenance}

Freely submitted; externally peer reviewed.

\section{Competing interests}

The authors have declared no competing interests.

\section{Acknowledgements}

We acknowledge Dr William D Thompson, consultant pathologist NHS Grampian, Mr Graham McHardy, data manager, Department of Pathology, University of Aberdeen, and Mrs Fiona Chaloner, formerly of the University of Aberdeen Data Management Team, for assisting in the construction of the study database.

\section{Discuss this article}

Contribute and read comments about this article on the Discussion Forum: http://www.rcgp.org.uk/bjgp-discuss

six melanomas annually, and concluded that there was no significant difference in survival for patients treated by the three groups. Melanomas excised in primary care were not considered in this previous study. A further Scottish study, reported by McKenna et al in 2004, found that patients treated initially by dermatologists survived significantly longer than those initially treated by plastic or general surgeons. ${ }^{13}$ In this study, differences in survival between the GP- and the dermatologytreated groups were non-significant and the authors concluded that this was because the GP group was small and because most GPs performing skin surgery in the study area did so in close cooperation with the local dermatology department. The present study has addressed both of these limitations without finding that GP excision compromises long-term outcome. An American study also reported that patients receiving their initial melanoma excision biopsy from a dermatologist had superior survival to those having the initial excision biopsy from a non-dermatologist. ${ }^{26}$ However, the obvious differences between the UK and US healthcare systems make these data harder to interpret. A Spanish study reported in 2006 also concluded that patients receiving their initial melanoma excision biopsy from a dermatologist had superior survival and recurrence-free intervals. ${ }^{27}$ Again, melanomas excised in primary care were not considered. None of these studies reported on morbidity outcomes following primary melanoma treatment. Faced by these conflicting data, and the fact that melanomas will continue to be excised in primary care, the present data are reassuring. In Australia, which has one of the world's highest incidences of melanoma, GPs excise the majority of melanomas and Australians have superior survival from melanoma compared to the UK.

\section{Implications for research and practice}

Patients who had their initial diagnostic excision biopsy for melanoma in primary care did not suffer poorer survival or increased morbidity when compared to those having their initial diagnostic excision biopsy performed in secondary care. This study has three key implications for the UK NHS. First, patients who have had a melanoma inadvertently excised in primary care can be reassured by the current evidence that this does not mean impaired survival or increased morbidity. Secondly, current guidelines, which view the primary care excision of melanoma as a management failure and insist upon all suspicious skin lesions being referred to secondary care, may not necessarily offer patients the best opportunity of timely diagnosis and superior long-term outcomes. Thirdly, the current study clearly signifies the need for a randomised controlled trial to definitively establish the role of initial excision biopsy in primary care in the diagnosis and treatment of cutaneous melanoma in the UK. The findings provide reassurance that such a trial can be safely conducted and, if appropriately designed, could determine the most cost-effective and clinically effective diagnostic and management pathway for melanoma in the future. 


\section{REFERENCES}

1. Cancer Research UK. Skin cancer incidence statistics. http://info. cancerresearchuk.org/cancerstats/types/skin/incidence/uk-skin-cancerincidence-statistics\#Trends (accessed 30 May 2013).

2. Marsden JR, Newton-Bishop JA, Burrows $L$, et al. Revised UK guidelines for the management of cutaneous melanoma. Br J Dermatol 2010; 163(2): 238-256.

3. National Institute for Health and Clinical Excellence. Improving outcomes for people with skin tumours including melanoma: the manual. London: NICE, 2006

4. Scottish Intercollegiate Guidelines Network. Cutaneous melanoma - a national clinical guideline. SIGN guideline number 72. Edinburgh: Scottish Intercollegiate Guidelines Network, 2003

5. Skellet A, Gibbs S, Handfield-Jones $S$, et al. Management of melanomas in primary care. Br J Dermatol 2011; 164(3): 680-682

6. Murchie P, Sinclair E, Lee AJ. Primary excision of cutaneous melanoma: does location of excision matter? Br J Gen Pract 2011; DOI: 10.3399/bjgp11X556272.

7. Chen SC, Pennie ML, Kolm P, et al. Diagnosing and managing cutaneous pigmented lesions: primary care physicians versus dermatologists. J Gen Intern Med 2006; 21(7): 678-682.

8. McWilliam LJ, Knox F, Wilkinson N, Oogarah P. Performance of skin biopsies by general practitioners. BMJ 1991; 303(6815): 1177-1179.

9. Herd RM, Hunter JAA, McLaren KM, et al. Excision biopsy of malignant melanoma by general practitioners in south east Scotland 1982-91. BMJ 1992; 305(6867): 1476-1478.

10. Khorshid SM, Pinney E, Newton Bishop JA. Melanoma excision by general practitioners in North-East Thames region, England. Br J Dermatol 1998; 138(3): 412-417.

11. Murchie P. Treatment delay in cutaneous melanoma: from diagnosis to definitive treatment. Qual Prim Care 2007; 15: 345-351.

12. Neal RD, Cannings-John R, Hood K, et al. Excision of malignant melanoma in North Wales: effect of location and surgeon on time to diagnosis and quality of excision. Fam Pract 2008; 25:(4) 221-227.

13. McKenna DB, Marioni JC, Lee RJ, et al. A comparison of dermatologists, surgeons and general practitioners surgical management of cutaneous melanoma. Br J Dermatol 2004; 151(3): 636-644

14. Askew DA, Wilkinson D, Schlucter PJ, Eckert K. Skin cancer surgery in Australia
2001-2005: the changing role of the general practitioner. Med J Aust 2007 187(4): $210-214$

15. Cancer Research UK. Skin cancer - survival statistics. http://info. cancerresearchuk.org/cancerstats/types/skin/survival/ laccessed 30 May 2013).

16. Australian Institute of Health and Welfare and Australasian Association of Cancer Registries 2010. Cancer in Australia 2010: an overview. Cancer series no. 60. AlHW cat no CAN 56. Canberra: Australian Institute of Health and Welfare, 2010

17. Harley K, Jones C. Quality of Scottish Morbidity Record (SMR) date. Health Bull 1996; 54: 410-417.

18. Kendrick S, Clarke J. The Scottish record linkage system. Health Bull 1993; 151: 72-79

19. ScottisH Informatics Project (SHIP). http://wnw.scot-ship.ac.uk/overview laccessed 30 May 2013).

20. Howe GR. Use of computerised record linkage in cohort studies. Epidemiol Rev 1998; 20(1): 112-121

21. The Scottish Government. Defining Scotland by rurality. http://uww.scotland.gov. uk/Topics/Statistics/About/Methodology/UrbanRuralClassification laccessed 30 May 2013).

22. The Scottish Government. Scottish index of multiple deprivation. http://unw. scotland.gov.uk/Topics/Statistics/SIMD laccessed 30 May 2013).

23. Dupont WD. Statistical modeling for biomedical researchers: a simple introduction to the analysis of complex data. 2nd edn. Cambridge: Cambridge University Press, 2008

24. Information and Statistics Division (ISD), NHS Scotland. Cancer statistics. Skin cancer. http://umw.isdscotland.org/Health-Topics/Cancer/Cancer-Statistics/ Skin/\#melanoma (accessed 30 May 2013).

25. Mackie RM, Bray CA, Hole DJ. Observational study of type of surgical training and outcome of definitive surgery for primary malignant melanoma. BMJ 2002 325(7375): 1276 .

26. Pennie ML, Sonn SL, Risser JB, et al. Melanoma outcomes for Medicare patients: association of stage and survival with detection by a dermatologist vs a nondermatologist. Arch Dermatol 2007; 143(4): 488-494.

27. Aviles JA, Lazaro P. Prognosis for cutaneous melanoma according to surgical department: comparatative study at a tertiary care hospital. Actas Dermosifiliogr 2006; 97(4): 247-252 